\title{
Study of Gujarati Diaspora with Special Reference To England and Canada
}

\author{
Mr.Virendra Singh Chundawat*
}

\begin{abstract}
Lots of studies have been done on Gujarati diaspora but not much is done on socio-cultural dimensions of life in host country and its impact in country of origin. Most migrants wanted to permanently settle in England and Canada.

Primary cause of immigration and settlement in host country is by economic reasons like economic inconvenience and less employment opportunities with low job securities. However it does not imply their dislike for their tradition, social structure and culture of natal community, which they are still preserving in host countries.

Encouraging factor for immigration and settlement of respondents was due to supporting family, kinship and caste networks in host countries. And their (NRGs) status of being successful in country of origin.
\end{abstract}

\section{Introduction}

The word Diaspora is originated from two Greek words dia-meaning through, speiro- meaning scattered. In Greek it means 'to disperse' and is based on a translation of the Hebrew word, Galut. It means movement of people from one place to another, whereby they shift their residence and in the Ancient Greece, the word referred to migration and colonization. Diaspora was originally used for Jewish people ousted from their homeland Israel and settled all over world. In Hebrew, "the term initially referred to the setting of colonies of Jews outside Palestine after the Babylonian exile and has assumed a more General connotation of people settled away from their ancestral homelands" (Shuval, 2003).Human civilization is outsized densely inhabited cluster which possesses definite territory, culture and sovereignty. Society is studied generally in terms of member people residing in it. But, during recent time, a new trend of studying society in terms of native people residing presently in foreign country has developed. This trend is called as Diasporic Studies.

Diaspora is a multifaceted social phenomenon which has attracted the attention of Social Scientists, Government, NGOs and policy makers. Research in the field of Diaspora particularly in Indian society started only after Independence and got momentum with globalization process. The word Diaspora is analyzed in terms of immigration of people to foreign lands. Many studies on Indian Diaspora have focused on migrant or indentured laborers to various countries. The diasporic study incorporates aspects of identity, culture, conflicts, multiculturalism, power, ethnicity etc. These include emigration to and settlement in foreign countries, their socio- economic profile, position in host and home countries, organization of socio-cultural life in host country, problem of socio- cultural adjustment and preservation of separate socio-cultural identity, relation with home country and impact on home country in terms of bringing of socio-economic development and changes. Basic reason for lighting the sociologist's interest in study of Diaspora and its emergence as the important subject title of sociology is its nature of influencing changes and adjustments in socio-cultural and economic life of migrant and its family left behind. International migration leaves an impact, which may be direct or indirect, on everybody in the concerned family. The movement of people across the international boarders has multiple impacts such as demographic, economic and social in both countries of the origin and destination. Moreover it influences the lives of people in areas as diverse as the rural regions of developing countries and great metropolises of the industrialized countries.

Diaspora has great bearing upon the economy, social structure, culture and play significant role in socio-economic development and socio- cultural changes in area of origin at local, regional and national level. These immigrants also act as ambassador in the country of their immigration by representing culture and society of origin. In view of such numerical and functional significance, several diasporic studies have been conducted on Gujarati diaspora. In the absence of adequate studies on Gujarati diaspora, the present workis an effort to achieve a broader understanding of the study of Gujarati diaspora with special reference to Englandand Canada.

* Mr.Virendra.Singh.Chundawat, PhD Student, Department of Sociology, Faculty of Arts, The M.S. University of Baroda 


\section{Objectives of study}

The major objectives of the present study are as follows:

1) To study the socio-cultural and economic background of Gujarati Indians who have migrated to England and Canada

2) To analyze socio-economic factors responsible for emigration.

3) To examine Gujarati Diaspora's contributions to the growth of the Indian economy and development of Gujarat: remittance and investments.

4) To study socio-cultural dimensions of Gujarati Diasporic Communities.

\section{Research Methodology used in present Study}

This study in the field of Gujarati Diaspora focuses on Socio-cultural aspect of migrants whose homeland in Baroda and Nadiad and has migrated to England and Canada. The sample size of the present study consisted of 200 respondents. Snowball- sampling technique was used to identify respondents. The data was collected through "interview schedule" coupled with observation technique and secondary data.

Profile of the Respondents

It is noted that majority of the respondents are having higher education (78\%) and doing labor and lower level white collar jobs. (69\%) of respondents are living in nuclear families. All 200respondentsin the study was found to be Hindus belonging to Patidars, Patels, Baniya, Brahmins and others. Majority of the respondents $(78 \%)$ were found in their young and working age group of 20-40 years. Most of them (62\%) were capable or become capable enough to purchase their own properties and they are living in their own houses and about $60 \%$ of respondents are married males.

\section{Gujarati Diasporic Communities and their Socio- Cultural Dimensions}

Present study shows that there is complete change in educational and occupational spheres of their life as all of them have taken up modern education and occupation. Again most of them have adapted themselves to the western mode of living which implies change in their work habits as well as life- style. However so far as their attitudes and practices regarding major social institutional spheres like marriage, family, kinship, caste and religion are concerned, continuity (tradition) is observed in case of most of these respondents. This is validated by the facts that majority of them not only believe in traditional conception of marriage as sacrament and unbreakable social bond but also follow religious rites and rituals during marriage $(64 \%)$. It has been noticed that (34\%) of the respondents favored the tradition of joint family. About $82 \%$ of the respondents are found to be believing in and practicing caste endogamy. Food habits have changed and traditional are replaced by Western food or junk food which is been accepted by 55\%.Many of them have not only kept their ancestral property in their native village $(48 \%)$ but have also purchased properties in nearby urban regions. To maintain the existence of family name and presence in natal society they (42\%) visit their natal region on the social occasions like marriage, festivals, and death etc at least once a year. Among the positive impacts $60 \%$ reported that regional differentiations which were found to be in country of origin are negligible or not been considered in host country. Rather than regional, national identity is mostly noted. Findings are also been supported by majority of respondents that in host country they do visit or attend or celebrate the festivals of other religions which was rare in country of origin. Again majority of them also reported about sending of remittances to their family members $(52 \%)$ and occasional financial help to Indian relative or caste fellow in the time of need and crisis $(54 \%)$. Similarly majority of them reported about giving substantial donation to the religious institutions, caste association for religious, educational and social purpose and village panchayat for the development work in their village or home region (34\%). Despite having these emotional bonds and socio- economic ties, most of them $(82 \%)$ reported their unwillingness to return back to India for resettlement due to their children's unwillingness for the same and physical discomfort in India.

\section{Life in host country}

Social position of migrants is considered to be lower in host country and is being compared at the levels of black population but as compared to other migrants from Asian countries, their position is better. They are still considered to be the outsiders and are not getting the status as one among others. Because of not major notable contribution, in general they are considered to be the 'receivers' and not the 'contributor'. Migrants are watched as population visiting the host country for earning and spending less there and saving the major earned portions. Their perception of such lower position is getting compensated partly by their satisfaction over higher income as counted in Indian currency value and partly by their higher position in India, particularly their home region where they are regarded as successful entrepreneur's, rich, and well-off persons commanding great respect. 
It is observed that majority of migrant's feel comfortable living and celebrating festivals in narrowed circle of relatives, caste fellows, regional and religious groups of Indian origin. The group celebration of religious festivals like Holi, Navratri, Diwali, Janmashtmi and National festivals like India's Independence Day with relatives' friends, caste fellows of their home region is another common patter of their socio-cultural life. Courtesy home visits to their relatives and friend belonging to above groups as well as weekly or fortnightly group meeting or get together in public places like temple is common feature of their social life.

\section{Summary and conclusion}

(1) Lots of studies have been done on Gujarati diaspora but not much is done on socio-cultural dimensions of life in host country and its impact in country of origin.

(2) Most migrants wanted to permanently settle in England and Canada.

(3) Primary cause of immigration and settlement in host country is by economic reasons like economic inconvenience and less employment opportunities with low job securities. However it does not imply their dislike for their tradition, social structure and culture of natal community, which they are still preserving in host countries.

(4) Encouraging factor for immigration and settlement of respondents was due to supporting family, kinship and caste networks in host countries. And their (NRGs) status of being successful in country of origin.

\section{Bibliography and References}

[1]. Basu, Aparna, Perspectives on Women, Canada and India, Bombay: Allied Publishers, 1995, Includes bibliographical references. Contributed papers of two seminars, organized by the Centre for Canadian Studies, University of Delhi, 1994.

[2]. Buchignani, Norman; Indra, Doreen Marie; Srivastiva, Ram, Continuous Journey: a Social History of South Asians in Canada, Toronto, Ont.: McClelland and Stewart in association with the Multiculturalism Directorate, Department of Secretary of State and the Canadian Government Pub. Centre, Supply and Services, Canada, 1985.

[3]. Chandrasekhar, S., From India to Canada: a Brief History of Immigration, Problems of Discrimination, Admission and Assimilation, Lajolla, Calif.: Population Review Books, 1986.

[4]. College of William and Mary. Department of Anthropology, Tradition and Transformation: Asian Indians in America, [Williamsburg, Va., U.S.A.]: Department of Anthropology, College of William and Mary, 1986

[5]. Choondawat P.S, Sharma. A and Chundawat.V.S. (2013) "Socio-Economic background of Gujarati Diapora in Canada: A case study of Baroda City" paper presented at U.G.C organized international seminar on "Indian Diaspora in various perspectives" at S.P.University during 11-12 March 2013

[6]. Das, RajaniKanta, "Hindustani Workers on the Pacific Coast, Berlin: W.de Gruyter\& Co., 1923.

[7]. Doshi, Mahendra K.; Verma, Bhupendra K., Who's who among Indian Immigrants in North America Directory", New York: Published by B.K.Verma and M.K.Doshi for Who's who Among Indian Immigrants in North America, inc., 1976.

[8]. Israel, Milton, The South Asian Diaspora in Canada: Six Essays, Toronto: Multicultural History Society of Ontario, 1987.

[9]. Jensen, Joan M., Passage from India: Asian Indian Immigrants in North America, New Haven: Yale University Press, 1988.

[10]. Johnston, Hugh J.M., The East Indians in Canada, Ottawa: Canadian Historical Association, 1984.

[11]. Johnston, Hugh J.M., The Voyage of the KomagataMaru: the Sikh Challenge to Canada's Colour Bar, Vancouver: University of British Columbia Press, 1989.

[12]. Josh, Sohan Singh, Tragedy of KomagataMaru, New Delhi: People's Pub. House, 1975.

[13]. Judge, Paramjit S., Punjabis in Canada: A Study of Formation of An Ethnic Community, Delhi: Chanakya Publications, 1994.

[14]. Trivedi J (Ed.) (2012). "Indian Diaspora in National and region context”, University Press, Sardar Patel University, V.V.nagar 